\title{
$\underline{\text { Integral assessment of national economy sustainable development }}$
}

Authors: Luc Hens; Olena V. Shkarupa; Oleksandra I. Karintseva; Mykola O. Kharchenko

Abstract: This study is devoted to sustainable development issues of Ukraine. The problems of assessing the sustainable development are discussed. It is shown that many indicators are insufficient to make decisions at the national level. It was proposed to define trends of the development of the national economy based on integral analysis of environmental, economic and social indicators. The criteria for the selection of the indicators, the standards and factors of development are the main prerequisites for a mechanism of sustainable development. A system of indicators is based on the statistical information and allows to determine a combined sustainability index for the economy. A three-level system of indicators is proposed as well as integrated index of sustainable development. The method allows to assess the development of the different regions of Ukraine and to identify the current trends. It allows to monitor dynamic changes due to the complex system of indicators.

Keywords: sustainable development; business; models; evaluation; region; indicators; ecological modernisation. 